\title{
Transcriptional regulation of early embryo development in the model legume Medicago truncatula
}

\author{
Sergey Kurdyukov • Youhong Song • \\ Michael B. Sheahan · Ray J. Rose
}

Received: 2 August 2013/Revised: 23 October 2013/ Accepted: 2 November 2013/Published online: 22 November 2013

(C) The Author(s) 2013. This article is published with open access at Springerlink.com

\begin{abstract}
Key message Spatial and temporal expression of coexpressed transcription factors provide a framework to investigate the integrated control of embryo size, vascularisation, meristem development and onset of seed filling in early embryogenesis of Medicago truncatula.

Abstract Cultivated legumes account for more than a quarter of primary crop production worldwide. The proteinand oil-rich seed of cultivated legumes provides around one-third of the protein in the average human diet, with soybeans (Glycine max (L.) Merr) being the single largest source of vegetable oil. Despite their critical importance to human and animal nutrition, we lack an understanding of how early seed development in legumes is orchestrated at the transcriptional level. We developed a method to isolate ovules from the model legume, Medicago truncatula Gaertn, at specific stages of embryogenesis, on the basis of
\end{abstract}

Communicated by P. Lakshmanan.

Dr. Michael Sheahan, our much-admired colleague, passed away in 2012.

Electronic supplementary material The online version of this article (doi:10.1007/s00299-013-1535-x) contains supplementary material, which is available to authorized users.

S. Kurdyukov · Y. Song · M. B. Sheahan · R. J. Rose ( $\square)$ Australian Research Council Centre of Excellence for Integrative Legume Research, School of Environmental and Life Sciences, The University of Newcastle, Callaghan, NSW 2308, Australia

e-mail: Ray.Rose@newcastle.edu.au

Present Address:

S. Kurdyukov

Kolling Institute of Medical Research, Kolling Building, Royal

North Shore Hospital, St Leonards, NSW 2065, Australia flower and pod morphology. Using these isolated ovules we profiled the expression of candidate homeobox, AP2 domain and B3 domain-containing transcription factors. These genes were identified by available information and sequence homology, and five distinctive patterns of transcription were found that correlated with specific stages of early seed growth and development. Co-expression of some genes could be related to common regulatory sequences in the promoter or $3^{\prime}$-UTR regions. These expression patterns were also related to the expression of B3-domain transcription factors important in seed filling (MtFUS3-like and MtABI3-like). Localisation of gene expression by promoter-GUS fusions or in situ hybridisation aided understanding of the role of the transcription factors. This study provides a framework to enhance the understanding of the integrated transcriptional regulation of legume embryo growth and development and seed filling.

Keywords Medicago truncatula - Embryogenesis . Ovules - Seed development - Transcription factors .

Homeobox genes

\section{Abbreviations \\ HD-ZIP HOMEOBOX LEUCINE ZIPPER \\ KNOX KNOTTED-LIKE HOMEOBOX \\ MtGEA Medicago truncatula Gene Expression Atlas \\ WOX WUSCHEL-related homeobox \\ WUS WUSCHEL}

\section{Introduction}

Fertilisation of the egg and central cell within an ovule by the male gametes triggers a process that produces a diploid 
embryo and triploid endosperm, and ultimately leads to the development of a seed. After fertilisation of the egg, the zygote undergoes an asymmetric cell division producing a two-cell embryo polarised along the apical-basal axis (Goldberg et al. 1994; Wang et al. 2012). In the model legume, Medicago truncatula, the program of embryonic development nears completion by around 8 days after anthesis, at which point a fully formed embryonic bodyplan and all specialised meristematic tissues are evident (Wang et al. 2012). Establishing an embryonic body-plan requires appropriate cell differentiation, which in turn necessitates a coordinated regulation of gene expression.

In Arabidopsis (Arabidopsis thaliana), a number of transcription factors act exclusively during embryogenesis, with many exhibiting precise spatiotemporal expression patterns (Park and Harada 2008; Le et al. 2010). Such specialised expression is necessary to establish axes of polarity, which in turn determine the correct placement and development of organs and tissues such as the vasculature, meristems and epidermis. While there are considerable data concerning the genetic regulation of early embryogenesis in Arabidopsis, with the exception of soybean (Le et al. 2007), little is known of analogous processes in legume species. Legume embryos display a wide range of forms and their protein- and oil-rich cotyledons supply much of the world's protein and plant oil needs (Graham and Vance 2003; Le et al. 2007). With its small-sized (500 Mb), diploid genome and short life cycle, M. truncatula (along with Lotus japonicus L.) has become the primary experimental model for legumes, being used to study nodulation, but also seed and embryo development (Cook 1999; Rose 2008; Cannon et al. 2009; Thompson et al. 2009; Rose et al. 2010). Moreover, M. truncatula is phylogenetically close to the most economically important, but less experimentally tractable legumes and displays large-scale synteny with other legumes (Choi et al. 2004; Cannon et al. 2006; Young and Udvardi 2009). Thus, knowledge generated in $M$. truncatula should be readily transferrable to important crop species, making it an important model for forage and grain legumes.

Substantive genomic resources exist for $M$. truncatula (Young and Udvardi 2009). For example, publicly available Affymetrix Gene Chip data for M. truncatula have been abridged in the interactive $M$. truncatula Gene Expression Atlas (MtGEA; Benedito et al. 2008). While the MtGEA summarises information on transcription factors involved in the latter stages of seed development, the early stages ( $<10$ days after anthesis) corresponding to embryogenesis are unrepresented by this resource. Studies by Verdier et al. (2008) investigating transcriptional regulation of seed filling in $M$. truncatula were carried out from 10 days after pollination. Obtaining sufficient embryonic material in $M$. truncatula has hindered investigations into the genetic regulation of early seed development in this species. The acquisition of temporal and spatial expression data and the identification of ciselements common to co-expressed genes can assist in making informed predictions of gene function.

We recently completed an investigation into the developmental biology of embryogenesis in M. truncatula from embryo sac to embryo maturation and oil and protein body formation (Wang et al. 2012). Here, we sought to provide a standardised method of collecting ovules at the same developmental stage to collect a uniform population of embryonic material to profile the expression of candidate transcriptional regulators of embryogenesis. By interrogating databases of expressed sequence tags and genomic sequences, we identified genes with homology to transcription factors active in flowers or seeds and, therefore, possibly involved in early seed development. In choosing the transcription factors for our analysis, we also considered their regulatory potential. Profiling the expression of 19 candidate genes by quantitative real-time PCR (qRT-PCR) revealed distinctive patterns of transcription during early seed development. We also related the timing of the expression of these genes to the transcription factor MtSERF1, essential for somatic embryogenesis in M. truncatula (Mantiri et al. 2008), and to genes related to seed filling. For selected candidates, we also performed RNA in situ hybridisation and promoterGUS experiments, which revealed embryo- and tissuespecific expression patterns. By analysing sequences outside the open reading frame of co-expressed genes, we discovered motifs with shared sequence similarity. Our data complement studies of seed embryo development in M. truncatula (Wang et al. 2012), providing a framework for understanding how transcriptional control orchestrates legume seed development.

\section{Materials and methods}

Plant growth

Plant materials were obtained from glasshouse-grown plants of $M$. truncatula Gaertn cv. Jemalong. The glasshouse had a $14-\mathrm{h}$ photoperiod and $23 / 19{ }^{\circ} \mathrm{C}$ day/night temperature regime.

\section{Ovule collection and RNA isolation}

Ovules were collected from flower buds ( 2 days before anthesis, as determined by bud size and petal colour; Stage 0 ), flowers at anthesis (Stage 1) and from pods at six developmental stages from 2-7 days after anthesis (Fig. 1; Table S1). For each of two independent experiments, 

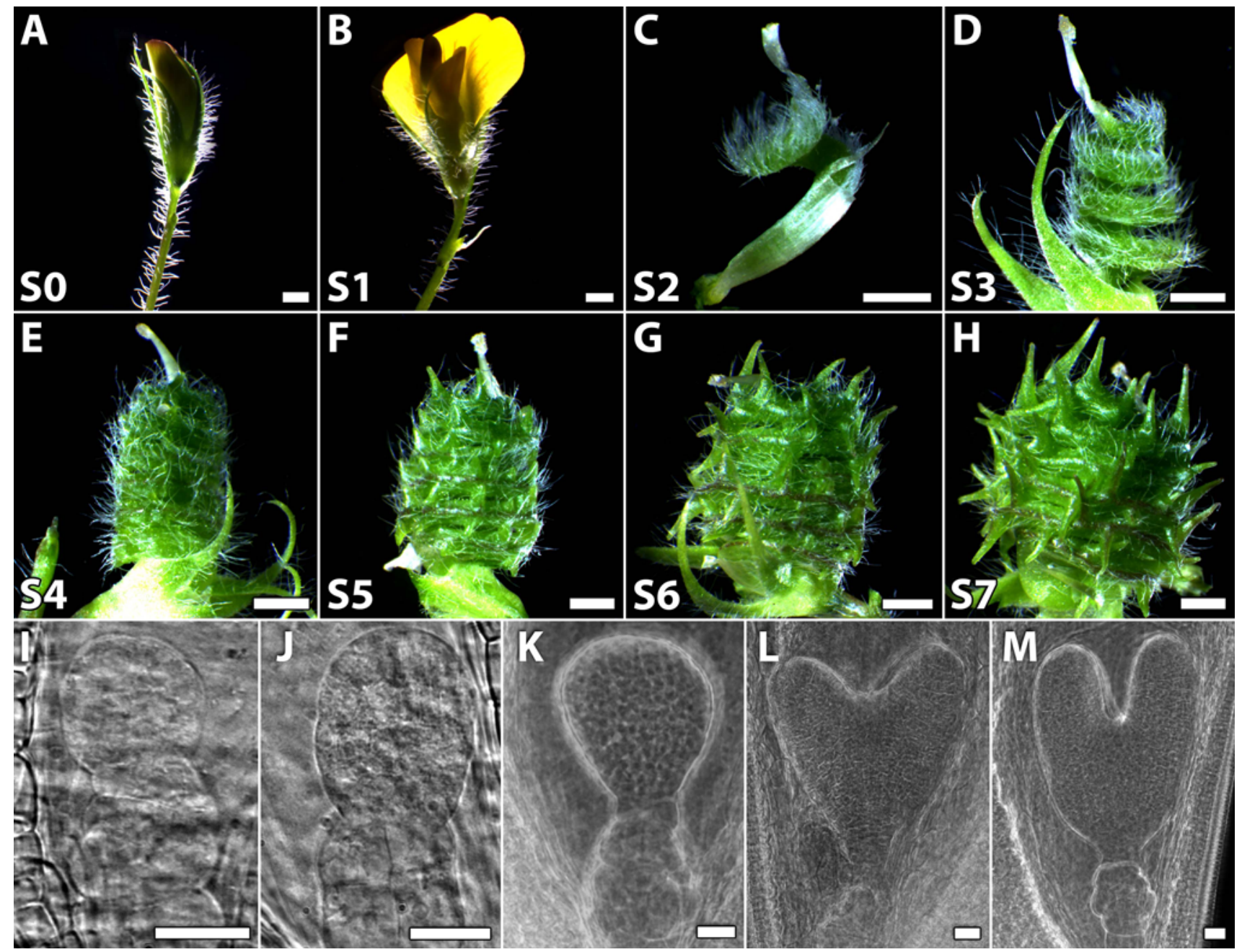

Fig. 1 Pods of Medicago collected for analysis and corresponding stages of embryogenesis. $\mathbf{a}-\mathbf{h}$ Images of flowers and pods (with petals removed) used to isolate RNA for qRT-PCR. a Stage 0: flower bud at 2 days before anthesis. b Stage 1: flower at anthesis. c Stage 2: early pod with one complete spiral. d Stage 3: pod with three complete spirals corresponding to early embryo development. e Stage 4: pod with five complete spirals and spine initials corresponding to early globular embryos. f Stage 5: pod with six spirals and immature spines corresponding to late globular embryos. g Stage 6: pod with six

ovules were collected at each developmental stage. To minimise variation, ovules were collected solely from the middle of each pod. Ovules were isolated from pods using a stereo dissection microscope (Leica, MZFLIII). In addition, only a small number of pods were collected at a time and kept on ice for not longer than $1 \mathrm{~h}$. Ovules were stored at $-80{ }^{\circ} \mathrm{C}$ until sufficient numbers were obtained. Ovules were suspended in ice-cold RNA lysis/binding solution from an RNAqueous-4PCR RNA isolation kit (Ambion). After isolation, the ovules were centrifuged and the supernatant transferred to a fresh tube. The pellet was immediately frozen in liquid nitrogen and homogenised with a plastic micropestle. Lysis/binding solution was spirals and elongated, maturing spines corresponding to heart-stage embryos. h Stage 7: Pod with six spirals, mature spines and increased girth corresponding to torpedo-stage embryos. i-m Zygotic embryos as visualised in ovules isolated from the middle portion of pods corresponding to stages S3-S7. i 8-16 cell-stage embryo. j Early globular-stage embryo. k Late globular-stage embryo. I Heart-stage embryo. m Torpedo-stage embryo. Bars $2 \mathrm{~mm}(\mathbf{a}-\mathbf{h})$ and $25 \mu \mathrm{m}(\mathbf{i}-$ m)

returned to the homogenate and vortexed for $10 \mathrm{~min}$. Cell debris was removed by centrifugation and RNA isolated (with DNase treatment) according to the manufacturer's instructions (Ambion). The methods for seed isolation and RNA extraction for MtFUS3-like and MtABI3-like gene expression during maturation were as described (Wang et al. 2012) and three replicates were used.

\section{Selection of transcription factors}

The transcription factors selected were likely to be involved in different stages of early embryo development (Tables S2 and S3). We had identified these transcription 
factors in somatic embryogenesis studies in M. truncatula (Mantiri et al. 2008; Chen et al. 2009) or where information was available from M. truncatula (Di Giacomo et al. 2008; Imin et al. 2007). We also identified transcription factors up-regulated in flowers and developing seeds in the MtGEA and from Arabidopsis using microarray data maintained in the Arabidopsis gene expression atlas (http:// www.ebi.ac.uk/gxa). BLAST searches (tblastx and blastx) were used to find homologues to these transcription factors in M. truncatula EST collections (DFCI Medicago Gene Index; http://compbio.dfci.harvard.edu/tgi) or from genomic sequences (GenBank; http://www.ncbi.nlm.nih.gov). The corresponding gene loci and protein sequences were obtained from the Mt3.5 genome release (http://www. medicagohapmap.org), or where unavailable, they were predicted directly using FGENESH (http://www.softberry. com). Full-length amino acid sequences of homologues from Arabidopsis, M. truncatula and rice (Oryza sativa) were then aligned using ClustalX 2.0.10 (Larkin et al. 2007). Phylograms (Supplementary Fig. 1A) were constructed from aligned sequences and drawn using the MEGA 5 program (Tamura et al. 2011) or (Supplementary Figs. 1B and 1C) were constructed from aligned sequences using the protein maximum likelihood, proml, programme in PHYLIP [Phylogeny Inference Package Version 3.69; (Felsenstein 1989)] and drawn with Dendroscope (Huson et al. 2007).

Gene expression analysis by quantitative real-time PCR

Synthesis of cDNA from $4 \mu \mathrm{g}$ of total RNA was performed using a Superscript III kit (Invitrogen) following the manufacturer's instructions. Gene expression was analysed by quantitative real-time PCR (qRT-PCR) using a RotorGene-Q (Qiagen). PCR reactions were carried out using glyceraldehyde 3-phosphate dehydrogenase (GAPDH; Mt8g109660) as a reference gene. GAPDH is a suitable reference gene for $M$. truncatula seed development based on geNORM software (Verdier et al. 2008), and our previous microarray and qRT-PCR studies (Mantiri et al. 2008). PCR master mixes were prepared with Platinum Taq (Invitrogen) using the provided buffer supplemented with $1.5 \mu \mathrm{M}$ SYTO9 (Invitrogen), $3 \mathrm{mM}$ dNTPs and $0.4 \mu \mathrm{M}$ of each primer. The qRT-PCR cycling conditions comprised an initial denaturation at $95{ }^{\circ} \mathrm{C}$ for $2 \mathrm{~min}$ followed by 40 cycles of $95{ }^{\circ} \mathrm{C}$ for $10 \mathrm{~s}, 60^{\circ} \mathrm{C}$ for $30 \mathrm{~s}$ and $72{ }^{\circ} \mathrm{C}$ for $30 \mathrm{~s}$. Dissociation analysis $\left(0.5^{\circ} \mathrm{C}\right.$ step $)$ was performed in every run and products checked by gel electrophoresis to ensure product uniformity. For each gene analysed, two biological and three technical repetitions were performed. Data analyses were performed using Q-Gene software (http:// download.gene-quantification.info/; Muller et al. 2002; Simon 2003). Q gene software uses mean normalised data and the $\Delta \Delta C_{\mathrm{T}}$ method to calculate relative expression (the calibrator was the lowest expression point for the gene investigated) and standard errors. Primers used for qRTPCR are listed in Table S2 and amplification efficiency based on serial dilution was greater than $90 \%$.

Construction and analysis of pMtWOX9-like::GUS fusion in somatic embryos

The promoter of a MtWOX9-like gene was amplified from M. truncatula genomic DNA by the primers $5^{\prime}$-CACCTT TAGCGCGCACCGTATTG-3' ${ }^{\prime}$ and 5'-ACAGTGTATGA CATAAAAACGGAAGAT- $3^{\prime}$ to give $1.65 \mathrm{~kb}$ of promoter sequence ending at the transcription start site $148 \mathrm{bp}$ upstream of the ATG start codon. The PCR amplicon was cloned into a pCR8/GW/TOPO entry vector (Invitrogen) and the orientation of the sequence confirmed by sequencing. The entry clone was transferred to the Gateway destination vector, pHGWFS7 (Karimi et al. 2005), using LR recombination and the resulting construct transformed into Agrobacterium tumefaciens [strain AGL1; (Lazo et al. 1991)] as described (Nolan et al. 2009). Transformation and culture of leaf explants was as described (Nolan et al. 2009). For GUS localisation studies, twenty calli from four independent transformations were cultured on P4:10:4 medium for 6 weeks and stained for GUS activity (Nolan et al. 2009).

RNA in situ hybridisation

Sequence-specific probes (as determined by blast checks) for in situ hybridisation were prepared by PCR from pooled cDNA using the primers 5'-CAATTCAATGTTGCAC CAAACTA- $3^{\prime}$ and 5'-ATTATCCACTGCAGTTCCAGC TA-3' for MtABI3-like (TC162720); 5'-TGGAATGGAA TGGAAACACAAGAAGTTT- $3^{\prime}$ and $5^{\prime}$-GGTGATAGT TATAAGGTACAGCAGCA-3' for MtLMI1-like (Mt1g 073710). Primer sequences for the MtWUS (MtWUSCHEL) probe and the RNA in situ hybridisation procedure were as described (Chen et al. 2009).

\section{Microscopy}

Ovules from each developmental stage for Fig. 1 were cleared using Hoyer's solution (Nolan et al. 2009). For in situ localisation, ovules were fixed in $4 \%$ formaldehyde and processed as described (Chen et al. 2009). Sectioned material was examined using a compound microscope (Zeiss; Axiophot), while cleared ovules and GUS-stained embryos were visualised with a stereo dissection microscope (MZFLIII). Images were captured with a digital camera (Zeiss, AxioCam HRc). 
In silico analysis

Identification of common elements in the promoters and $3^{\prime}$ untranslated regions ( $3^{\prime}$-UTRs) of co-expressed genes was performed using MClip with default cut-off of $1 \mathrm{e}^{-3}$ [(Frickey and Weiller 2007); http://bioinfoserver.rsbs.anu. edu.au/utils/mclip]. Sequences up to $4 \mathrm{~kb}$ upstream of the start codon for promoters and $1 \mathrm{~kb}$ downstream of the stop codon for $3^{\prime}$-UTRs were aligned and then analysed by MClip.

\section{Results}

Linking the early stages of embryogenesis in M. truncatula to pod morphology

We defined eight stages of early seed development (S0-S7; Table S1) - flower buds at 2 days before anthesis (S0), flowers at anthesis (S1) and six stages of pod development (S2-S7) that encompassed early embryogenesis (8-16 cell embryos) until the torpedo stage of embryogenesis (Fig. 1). The approximate timeframe, relative to anthesis, for collecting flowers and pods is given in Table S1. We found that embryo development varied with the time after anthesis, even though plants were of the same age and grown under identical conditions. However, by isolating ovule populations from pods defined by morphological criteria, we could isolate uniform populations of ovules containing embryos at a similar developmental stage. The criteria we used to define pod morphology were the number of pod spirals, developmental stage of pod spines and pod girth (Fig. 1). We distinguished pod stages S2-S4 primarily by the number of spirals present, with a single complete spiral in S2 pods, three in S3 pods and five in S4 pods. Pods at the S4 stage also exhibited spine initials (Fig. 1c-e). The presence of six complete spirals and immature spines whose length did not exceed the width of an individual pod spiral marked the S5 stage (Fig. 1f). Spines of S6 pods were longer than the width of an individual pod spiral and slightly bent, while S7 pods possessed thicker spines again and an increased pod girth relative to S6 pods (Fig. 1g, h). We did, however, find it essential to measure the time elapsed between S6 and S7 pods, as S7 pods were often indistinguishable from older pods (Table S1). The developmental stage of embryos corresponding to ovules isolated from S3 to S7 pods is shown in Fig. 1i-m. The uniformity of ovule development was confirmed by routinely examining embryos isolated from randomly selected ovules. It is difficult to identify embryos at the 1-4 cell stage and during sectioning; the embryo is often lost as it is not well attached to surrounding tissue. Thus, ovules of a specific developmental stage can be isolated, without the need for embryo isolation or sectioning and laser capture microdissection.

Selection of transcription factors for expression profiling

Among the 14 homeobox genes we selected, six belong to the WUSCHEL/WUSCHEL-RELATED HOMEOBOX (WUS/WOX) gene family, five to the HOMEOBOX LEUCINE ZIPPER (HD-ZIP) gene family and three to the KNOTTED1-LIKE HOMEOBOX (KNOX) gene family. In addition to the homeobox genes, we selected a $D N A$ BINDING WITH ONE ZINC FINGER (DOF) transcription factor, $B A B Y B O O M$ which contains two AP2/ERF DNAbinding domains, SOMATIC EMBRYO-RELATED FACTOR 1 (MtSERFl) which contains a single AP2/ERF domain and two genes from the B3 DOMAIN-CONTAIN$I N G$ transcription factor family (FUS3-like and ABI3-like). The loci for these genes in the M. truncatula genome, corresponding to the closest Arabidopsis homologue and Affymetrix $M$. truncatula GeneChip probesets used to examine gene expression are listed in Table S3. Table S3 indicates what was known of the expression of these genes in Medicago truncatula, based predominantly on the MtGEA. Using qRT-PCR to profile the expression of these transcription factors, we identified five overall types of expression patterns (Fig. 2).

\section{Group I genes}

Group I(A) genes comprised those showing decreased expression during ovule and embryo development (S0-S7; Fig. 2a-e). The MtWOX4-like (Fig. 2a), MtWOX1-like (Fig. 2b), HD-ZIP3 (Fig. 2c) and HD-ZIP4 (Fig. 2d) had a peak expression at S0, 2 days before anthesis at the ovule development stage. The HD-ZIP5 gene had high expression at the ovule development stages ( $\mathrm{S} 0$ and $\mathrm{S} 1$ ), but peaked at the earliest stage of embryogenesis, S2, before declining (Fig. 2e). The three Group I(B) genes [HD-ZIP2 (Fig. 2f), MtKNOX7 (Fig. 2g) and MtDOFl (Fig. 2h)] had similar expression to the Group 1(A) genes during ovule and early embryo development; but at the torpedo stage (S7; Fig. 2f-h), expression started to increase again.

\section{Group II genes}

The Group II genes, MtWUS (Fig. 2i) and MtLMI1-like (Fig. 2j) had a "U" shaped profile. Quite clearly there were two high points of expression at S0 and S7, in the ovule development and torpedo stages. In the case of these two genes, we carried out in situ hybridisation studies. In torpedo-stage embryos MtWUS was strongly expressed in the organiser region (Fig. 3a), consistent with previous studies 
Group I (A)

A

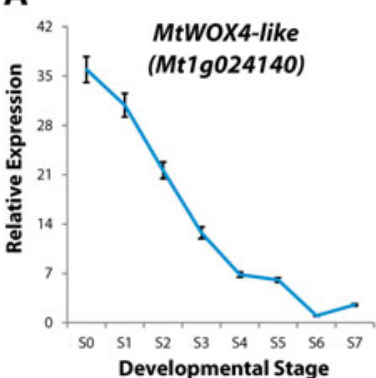

B

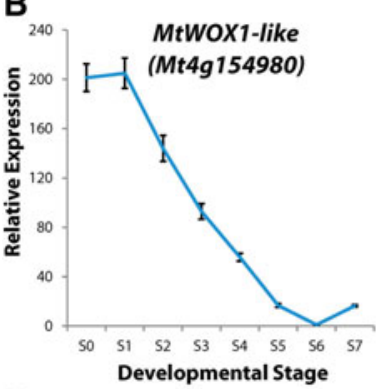

C

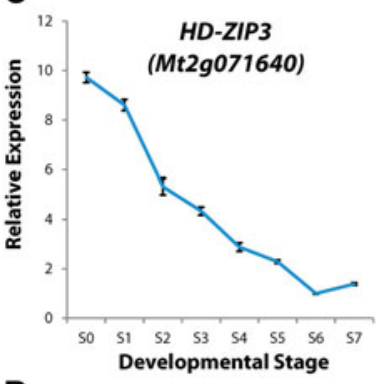

D

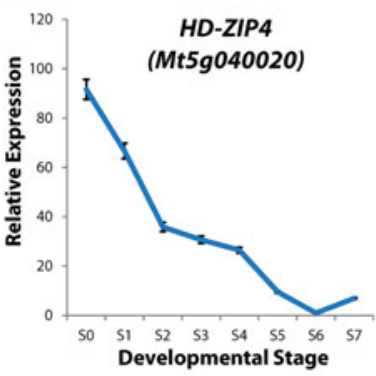

E

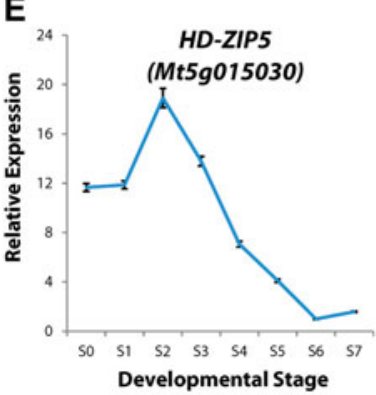

Group I (B)

F

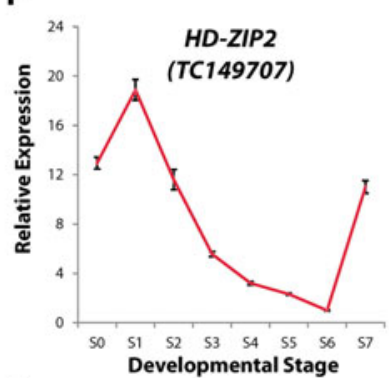

G

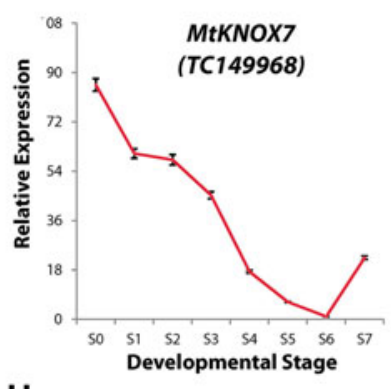

H

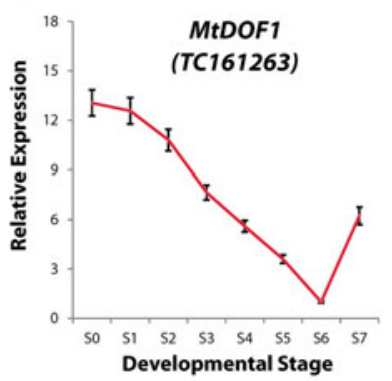

Group II

I

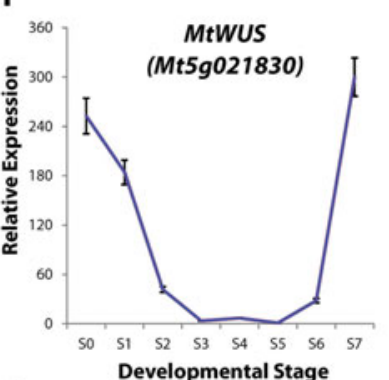

J

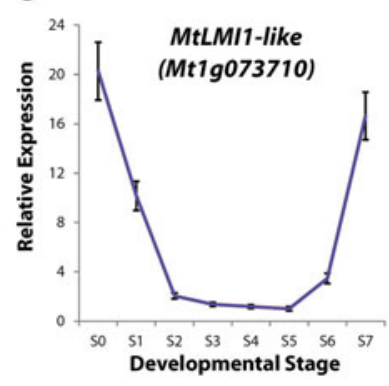

Group III (A)

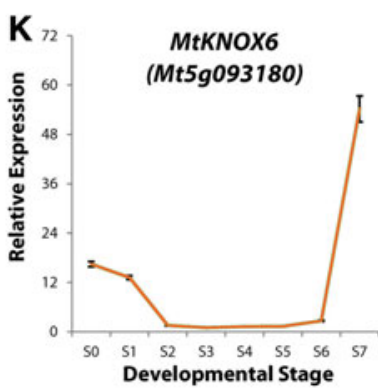

L

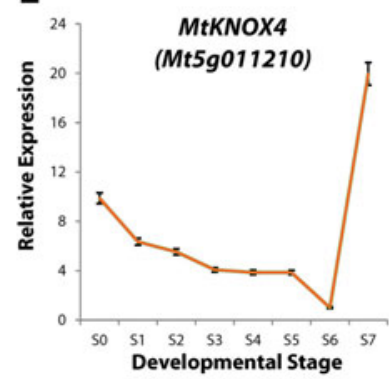

Group III (B)

M

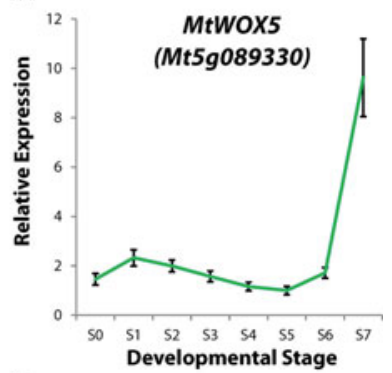

N
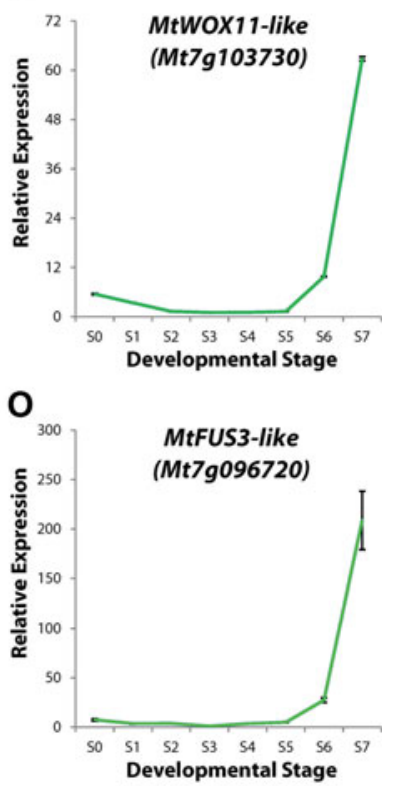

P
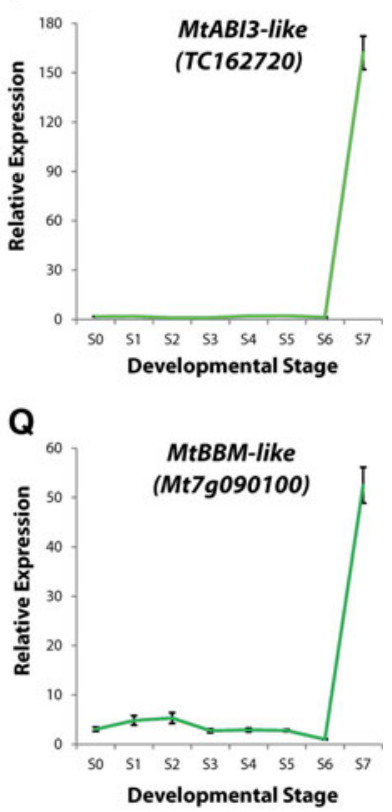
4 Fig. 2 Expression profile of 17 transcription factors in Groups I, II and III during ovule and embryo development. RNA was extracted from ovules at eight developmental stages $(\mathrm{S} 0-\mathrm{S} 7)$ as represented in Fig. 1, with genes grouped on the basis of expression pattern. ae Group I(A): continuously down-regulated during ovule and embryo development. f-h Group I(B): down-regulated during ovule and embryo development and then up-regulation commenced in torpedostage embryos. i, j Group II: high expression in ovule development and very early embryogenesis, inactive during early embryogenesis and markedly up-regulated during heart- and torpedo-stage embryogenesis. k, l Group III(A): some expression in ovule development and very early embryogenesis then down-regulated until marked increase in expression in torpedo-stage embryos. m-q Group III(B): high expression only in late heart- and torpedo-stage embryogenesis. Genes colour-coded to indicate members common to a transcription factor group. Standard errors indicated

(Chen et al. 2009); although there was some background on the embryo edge. There was no in situ hybridisation in the earlier stage embryos (Fig. 3b, c), consistent with qRTPCR results. WUS was expressed in ovule development (Fig. 2i) as occurs in Arabidopsis (Groß-Hardt et al. 2002).

The M. truncatula homologue of Arabidopsis LATE MERISTEM IDENTITY1 (MtLMI1-like) encodes a Class I
HD-ZIP protein with an expression profile (Fig. 2j) that closely resembles MtWUS (Fig. 2i). RNA in situ hybridisation revealed that expression of MtLMII-like localised throughout the whole embryo at the torpedo stage with a notable absence of expression in the hypophysis and suspensor (Fig. 4a). The expression of MtLMII-like was, however, particularly concentrated in the vascular procambium in torpedo-stage embryos (Fig. 4b, c). MtWUS and MtLMII-like contained two common promoter elements-one consisting of $11 \mathrm{bp}$ of identical sequence, and the other $17 \mathrm{bp}$ of interrupted sequence with an overall identity of $71 \%$ (Fig. 5a).

\section{Group III genes}

Group III(A) genes were highly expressed during the torpedo stage (S7; Fig. 2k, 1), but with moderate expression in the ovule development stage. Group III(B) genes dramatically increased expression at the torpedo stage (Fig. $2 \mathrm{~m}-$ q). These genes are known to be associated with both embryo development and seed filling (Boutilier et al. 2002; Haecker et al. 2004; Verdier and Thompson 2008). Despite
Fig. 3 Expression localisation for MtWUS by in situ hybridisation. a Torpedo-stage embryo. b Globular-stage and c late globular-stage transitioning to heart-stage embryo show no signal. Bars $50 \mu \mathrm{m}$

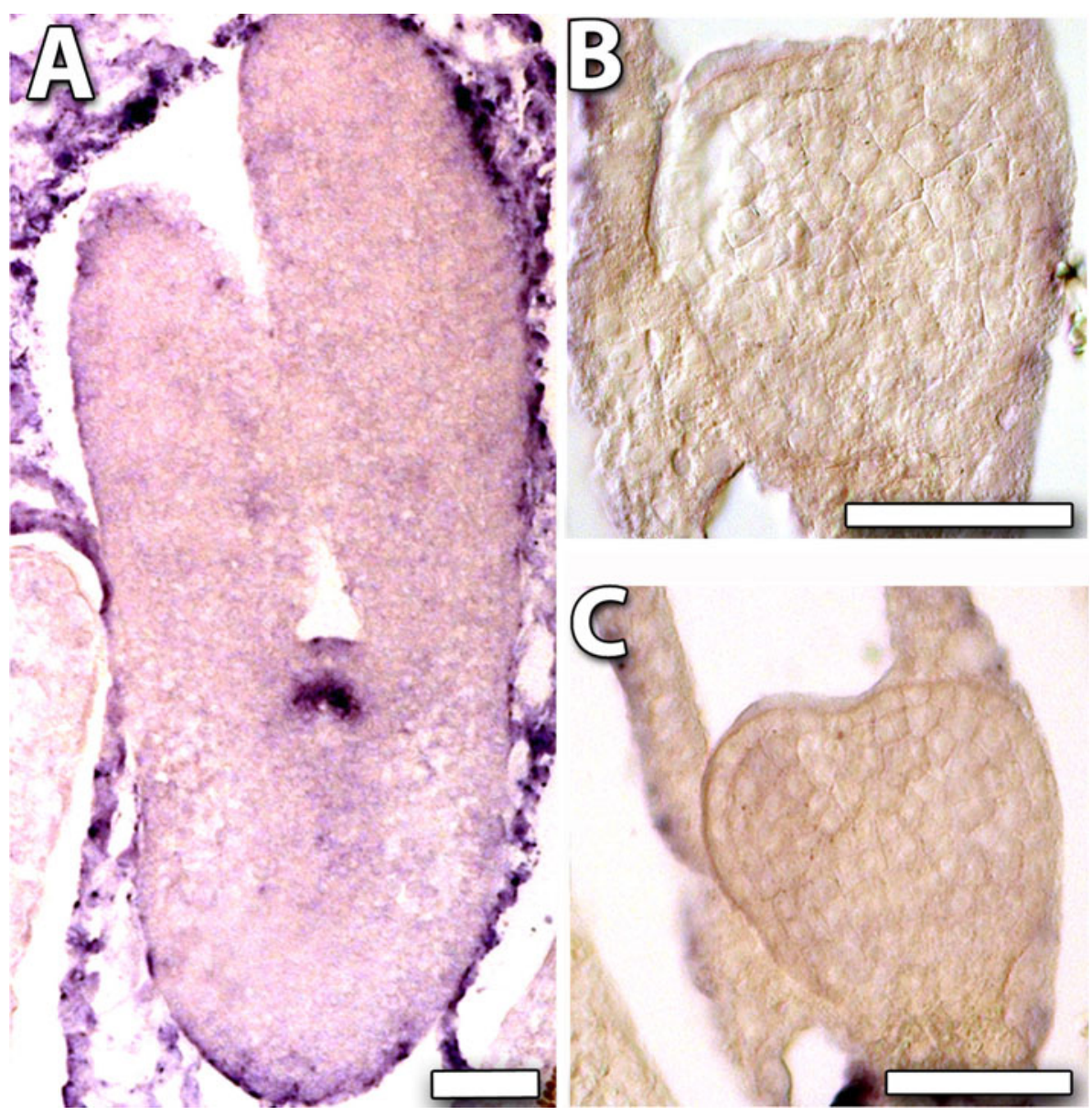




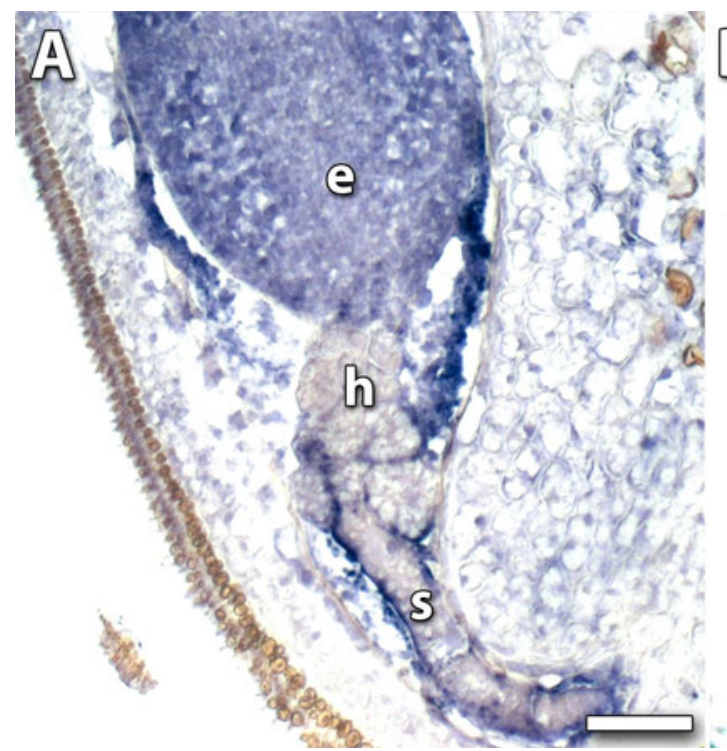

Fig. 4 Expression localisation of MtLMI-like genes. In situ hybridisation against the MtLMI1-like (Mt1g073710) gene expression. a Early torpedo-stage embryo (e) with no signal in the hypophysis

their distinctive cellular functions, MtBBM and MtFUS3like exhibited a similar expression profile. Interestingly, both genes contain a 23-bp motif within their $3^{\prime}$-UTR that is $78 \%$ identical and contains a 12-bp stretch of complete identity (Fig. 5b). It is possible the motif represents a miRNA target, but it is more likely to be a cis-element recognised by a DNA-binding protein, as it is present on the sense strand in $M t B B M$ yet on the antisense strand in MtFUS3-like.

Although there are no previous reports of cis-elements common to MtWUS and MtWOX5 promoters, we found relatively long stretches (28 and $20 \mathrm{bp}$ ) of homologous sequence in these promoters from $M$. truncatula, which shared 61 and $75 \%$ identity, respectively (Fig. 5c). Furthermore, a GAGA-like element identified in soybean (Sangwan and O'Brian 2002) was present in the promoters of MtWUS and MtLMI in expression Group II, MtKNOX6 in expression Group III(A) and MtWOX5 in expression Group III(B) (Fig. 5d). These four genes were all strongly up-regulated at the torpedo stage.

In legume seed, a major interest is in the regulation of accumulation of storage products in the developing cotyledons. The expression of the ABI3 transcription factor is associated with storage accumulation and controlled desiccation (Verdier and Thompson 2008). In situ hybridisation showed expression throughout the torpedo-stage S7 embryo (Fig. 6a). After the S7 stage, the expression of MtABI3-like continued to increase as the cotyledons developed, seed filling, then desiccation occurred (Fig. 6b). The expression of MtFUS3-like associated with oil and protein accumulation continued after $\mathrm{S} 7$ and peaked about 15 days after anthesis (Fig. 6c).
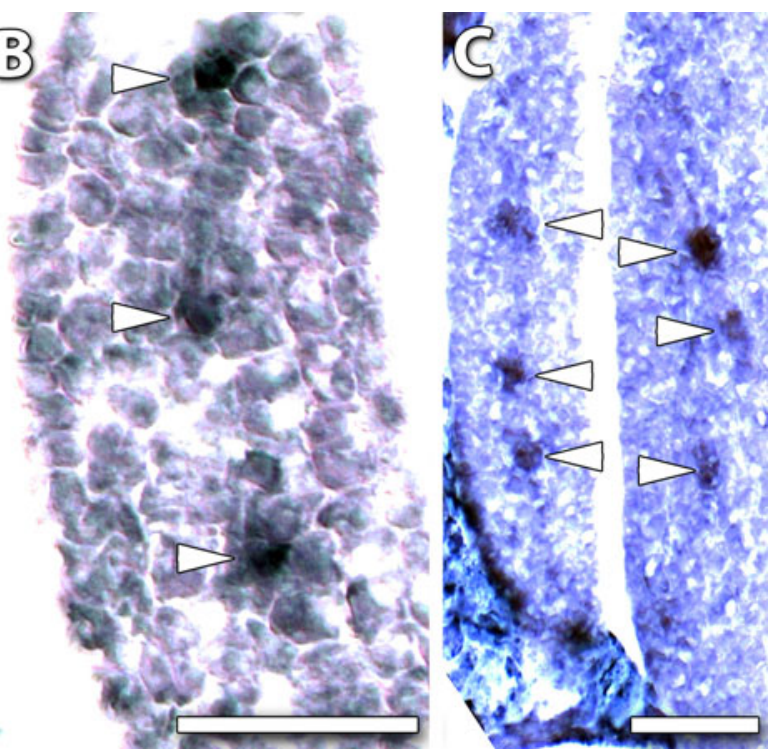

(h) or suspensor (s). b, c Transverse sections of cotyledons in a torpedo-stage embryo showing a concentration of signal in forming vascular tissue (arrowheads). Bars $50 \mu \mathrm{m}$

\section{Group IV and Group V genes}

In Group IV, there is a single gene (MtWOX9-like). This was the only gene that was progressively up-regulated during ovule and embryo development (S0-S7, Fig. 7a). To examine the localisation of MtWOX9-like expression, we created transgenic somatic embryos expressing a MtWOX9-like promoterGUS fusion ( $p M t$ WOX9-like::GUS). Staining for GUS activity in this instance revealed a signal exclusively in somatic embryos and absent from the surrounding callus (Fig. 8a-c). The expression of MtWOX9-like localised throughout the embryo until at least the early torpedo stage (Fig. 8c).

In Group V, there is also a single gene (MtSERF1), This is the only gene which had a peak of expression at the S3 stage (Fig. 7b). MtSERF1 is involved in somatic and zygotic embryogenesis in M. truncatula (Mantiri et al. 2008), and the data presented were obtained from this study.

\section{Discussion}

In discussing the data, we examine the different transcriptional regulators in the context of ordered growth and development stages in early embryogenesis.

Ovule development and early embryonic cell divisions (S0-S2)

The transcription factors examined show peak expression [Group I(A) and Group I(B)] or one peak of expression (Group II) during this phase. Two WOX genes and MtWUS, $M t D O F 1$, five $H D$-ZIP genes (including MtLMII-like) and 
A

MtWUS
MtLMI1-like

MtWUS

MtLMI1-1ike

Consensus

B

Mt BBM

MtFUS3

Consensus

C

MtWUS

MtWUS

MtWOX5

MtWUS

MtWOX5

MtWUS

MtWOX5

Consensus

MtWUS

MtWOX5

Consensus

D

MtWOX5

MtKNOX6

MtLMI1-1ike

MtWUS

MtWUS

Consensus
CATCTCTCTGT

CTCTCTGT

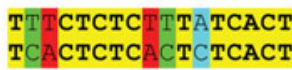

TYWCTCTCWYTMTCACT
$250 \mathrm{bp}$

$1.58 \mathrm{~kb}(-)$

$190 \mathrm{bp}$

$700 \mathrm{bp}$

$60 \mathrm{bp}$

$240 \mathrm{bp}(-)$
CTTGAAGA GGAAGATAGTTTAT
CTGGAACATTCAAGATAATTTAT

CTKGAASAWKSAAGTAATTTAT
GGGACTAAAA TGAAAAGTTGACATATTT GGGATTAAAAC GAAAAATTGATATATTT GGG TTACAAGTGTTACATGGACATATTT

GGGACTAAAA TGAAAAGTTGACATATTT GGGTTACAAG̈TGTACATGGACATATTT

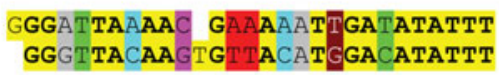

GGGATTAAAASTGWWAAATKGACATATTT

CCGGTTTAATACACGCCTTA

CCGGCTCAATGAACGACTTA

CCGGYTYAATRMACGMCTTA

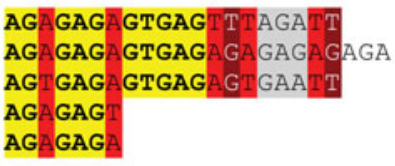

AGAGAGAGTGAGAGTGAATAGA
Fig. 5 Sequence elements in co-expressed and orthologous genes. a Region upstream of the MtWUS and MtLMI1-like start codon contains two common sequence elements. b A common sequence element in the $3^{\prime}$-UTR of MtBBM and MtFUS3-like. c Conserved sequence elements in the region upstream of the MtWUS and MtWOX5 start codon. Upper alignment for the first motif represents

$$
\begin{array}{ll}
3 \mathrm{~kb} & (-) \\
2.6 \mathrm{~kb} & \\
0.76 \mathrm{~kb} & (-) \\
3 \mathrm{~kb} & (-) \\
0.76 \mathrm{~kb} & (-) \\
& \\
2.6 \mathrm{~kb} & \\
0.76 \mathrm{~kb} & (-) \\
& \\
& \\
2.3 \mathrm{~kb} & (-) \\
0.58 \mathrm{~kb} & (-)
\end{array}
$$

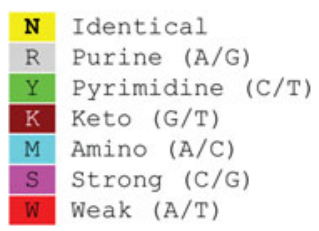

the two individual motifs in the MtWUS promoter aligned to the MtWOX5 promoter motif, whereas subsequent alignments show individual MtWUS motifs aligned to the MtWOX5 motif. d Upstream regions of the co-expressed MtWOX5, MtKNOX6, MtLMI1-like and $M t W U S$ genes contain a GAGA-like cis-element originally identified in soybean
A

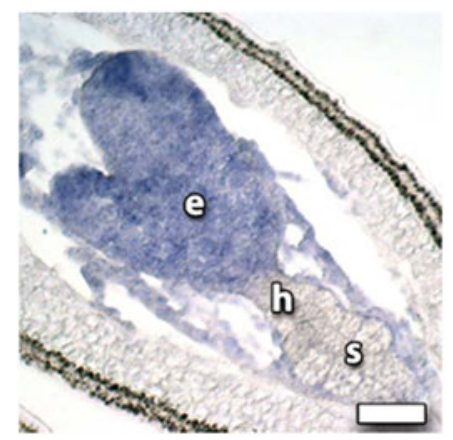

B

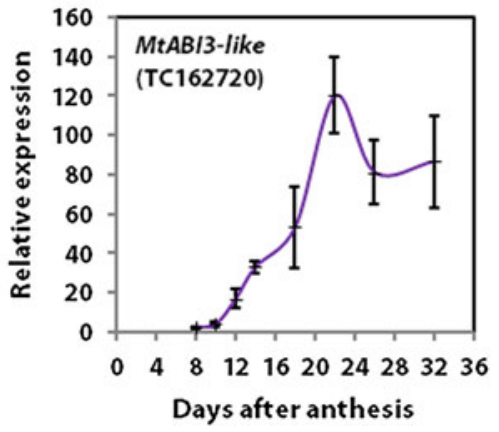

C

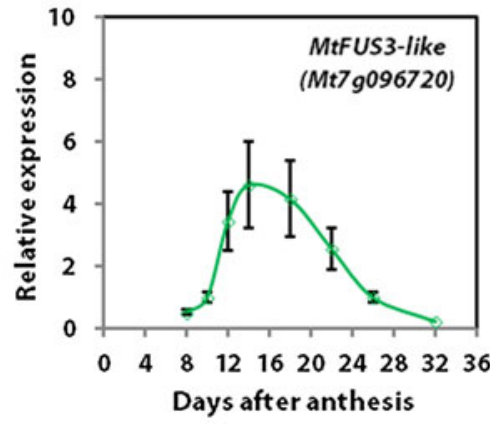

Fig. 6 Expression of ABI3-like and FUS3-like genes. In situ hybridisation (a) of $A B I 3$ shows expression throughout the torpedostage $\mathrm{S} 7$ embryo with signal localised to the embryo, (e) but absent from the hypophysis (h) and suspensor (s). Expression profile during cotyledon development and seed filling is shown for $A B I 3$ (b) and FUS3 (c). Bar $50 \mu \mathrm{m}$ 
Fig. 7 Expression of Group IV and $\mathrm{V}$ genes in ovule and embryo development.

Expression profile of $M t W O X 9$ like (a) and MtSERF1 (b). Note MtSERF1 data obtained from Mantiri et al. (2008).

Supplementary Fig. S2 and redrawn, with approval (http:// www.plantphysiol.org and Copyright American Society of Plant Biologists)
Group IV
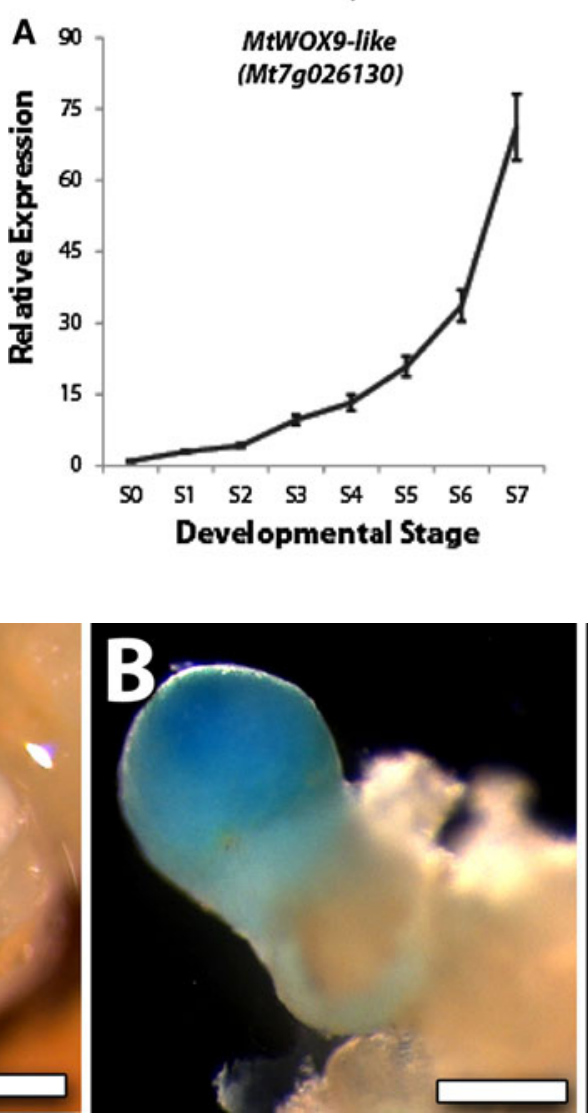

Group V
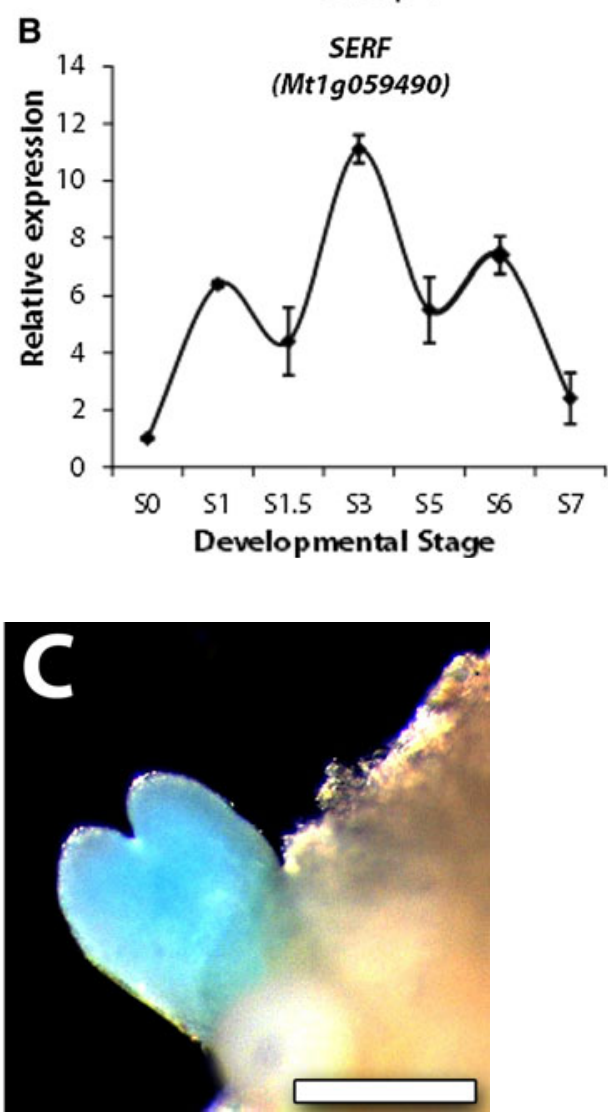

Fig. 8 Localisation of MtWOX9-like expression. a-c GUS expression in somatic embryos driven by the MtWOX9-like promoter. a Embryospecific expression in a proembryonic mass. b Globular-stage embryo. c Early torpedo-stage embryo. Bars $50 \mu \mathrm{m}$

one $K N O X$ gene are in this category. Based on the data here and from the literature it is likely that MtWOX l-like, MtWOX4-like, MtDOF1-like and MtLMI1-l1ke expression is associated with vascularisation; while $M t W U S$, MtHDZIP2,3,4 and 5, and MtKNOX7 expression is involved with ovule development and early embryonic cell divisions.

The MtWOX4-like and MtWOX1-like genes showed highest expression in pre-anthesis ovules (S0; Fig. 2a, b), decreasing during early embryogenesis. In Arabidopsis and tomato (Solanum esculentum), WOX4 is involved in procambium development (Hirakawa et al. 2010; Ji et al. 2010). Similarly, AtWOXI is active in initiating the vascular primordium of Arabidopsis cotyledons (Haecker et al. 2004). In maize (Zea mays) embryos, WOX4 marks the provasculature in hypocotyls (Nardmann et al. 2007). MtWOX4-like is strongly expressed in highly vascularised callus of $M$. truncatula wild-type Jemalong in response to auxin plus cytokinin (Chen and Rose, unpublished). The data at the SO-S2 developmental stage may reflect vascularisation of the funiculus in the developing ovule. Recent studies have identified STENFOLIA as the MtWOX1-like gene, which regulates leaf vascular patterning in $M$. truncatula and is also expressed at the base of ovules (Tadege et al. 2011, Table S3). The gene represented by TC161263, which we have called MtDOF 1, is similar to DOF4.6 from Arabidopsis (At4g24060). MtDOF1 expression continually decreases during ovule development from stages S0-S6, but with increasing expression in torpedo-stage ovules (S7, Fig. 2h). In Arabidopsis DOF4.6 plays a role, along with $A t H B-8$, in defining pre-procambium cell identity (Gardiner et al. 2010). MtLM1-like may also be involved in vascularisation (Fig. 4).

The expression of MtWUS in ovules isolated from flowers (S0 and S1) likely reflects an involvement in ovule development as occurs in Arabidopsis (Groß-Hardt et al. 2002), where it is expressed in the nucellus. Expression of MtWUS is still detectable in ovules from S2 pods, but not detected again until heart- and torpedo-stage embryos are formed (S6-S7 pods; Figs. 2i, 3a-c). In Arabidopsis, WUS expression appears in early globular (16-cell)-stage embryos (Mayer et al. 1998). Both qRT-PCR and in situ hybridisation demonstrate that in M. truncatula, MtWUS is not expressed at this stage in zygotic embryogenesis (Figs. 2i, 3a-c). Moreover, expression in heart-stage ovules (S6, Fig. 2i) remains low, as supported by in situ hybridisation (Fig. 3b, c). We compared the promoter regions (up 
to $4 \mathrm{~kb}$ upstream of the start codon) of AtWUS and MtWUS. Although we identified more than five conserved elements, the 57-bp spatial control region identified as essential for AtWUS promoter activity in the Arabidopsis stem cell niche (Baurle and Laux 2005) was absent from the MtWUS promoter. This difference may be related to the relative late expression in Medicago or the hypothesis that MtWUS is involved in the nodule meristem development as well (Couzigou et al. 2012).

Four HOMEOBOX LEUCINE ZIPPER (HD-ZIP) genes express similarly to MtWOX4-like and MtWOX1-like in the S0-S2 phases. The HD-ZIP class I and class II transcription factors have been associated with hormone-regulated cell growth and differentiation in response to environmental stimuli (Harris et al. 2011). Class I genes are involved in ABA responses and Class II genes in auxin responses. Both Class I (MtHD-ZIP2 and MtHD-ZIP4) and Class II (MtHDZIP3 and MtHD-ZIP5) genes have relatively high expression in the S0-S2 stages in the earliest stages of ovule and embryo development. A class I gene studied in $M$. truncatula ( $M t H B 1$, a homologue of $A t H B 7$ and $A t H B 12)$ is expressed in lateral root meristems induced by stress (Ariel et al. 2010). MtHD-ZIP3 (Mt2g071640) in the MtGEA (Mtr.12147. 1.S1_at probeset) has high expression in 2-week callus (Jemalong 2HA) when embryos are being initiated in response to auxin plus cytokinin. The class II $H D-Z I P 2$ gene represented by TC149707 and most closely related to AtHB2 in Arabidopsis (At4g16780; Supplementary Fig. 1B) though having a similar expression to the other HD_ZIP gene in the S0-S6 stages shows increased expression in torpedo-stage ovules (S7; Fig. 2f).

Class I and Class II KNOTTED1-like homeobox (KNOX) genes are characterised by the presence of a homeodomain and MEINOX (also known as KNOX) domains (Mukherjee et al., 2009). MtKNOX7 is a class II gene, and class II is less well studied. However, it is known that the MEINOX domain of class I KNOX genes can interact with other proteins such as BELL (Hay and Tsiantis 2010) to reduce GA levels (binds to promoters of GA20oxl and GA2oxl) and increase cytokinin levels (binds to promoter of IPT7). Such hormone influences favour cell division.

Forming the globular-stage embryos (S3-S5)

The pattern of increasing WOX9-like expression during embryogenesis, as shown by qRT-PCR and also the GUS data in somatic embryos, is consistent with the maintenance of cell proliferation as the embryo develops. In Arabidopsis, WOX9 is required for the maintenance of cell division in the embryo and suspensor (Wu et al. 2007). Importantly, MtWOX9-like in Medicago serves as a specific marker of somatic embryos that is active from the earliest stages of embryogenesis (Fig. 8a). Indeed, homologues of
MtWOX9-like in Brassica napus (Malik et al. 2007) and Vitis vinifera (Gambino et al. 2011) have also been identified as excellent markers of somatic embryogenesis. $\mathrm{Wu}$ et al. (2007) also showed that WOX 8 and WOX2 act redundantly to promote cell division in Arabidopsis, but with a minor role compared to WOX9.

Apart from the MtWOX9-like gene, the only other gene showing increasing expression in the S2-S5 stages is MtSERF1, while MtSERF1 is essential for somatic embryogenesis its function is not known. Previous in situ hybridisation studies have shown expression throughout globular-stage embryos and localisation in the organiser region in the heart-stage embryo (Mantiri et al. 2008). This suggests that it may be related to regulating the growth of the globular-stage embryo and the development of the organiser region, though more work is necessary. SERF1 is ethylene dependent in somatic embryogenesis (Mantiri et al. 2008; Zheng et al. 2013). In Medicago, MtSERF1 is dependent on auxin, cytokinin and ethylene (Mantiri et al. 2008).

Heart and torpedo stage and formation of apical meristems (S6-S7)

In the heart stage zygotic embryo of M. truncatula, MtWUS expression has previously been shown to localise to the organiser region of the shoot pole of the heart-stage embryo (Chen et al. 2009). In contrast to Arabidopsis where WUS expression first appears in early globular (16-cell)-stage embryos (Mayer et al. 1998), there is no expression at this stage in M. truncatula. Interestingly, WUS expression in embryogenic cultures of Arabidopsis is induced by auxin in Arabidopsis, but by cytokinin in M. truncatula (Chen et al. 2009; Su et al. 2009). The primary amino acid sequence and domain structure of WUS is conserved between Arabidopsis and M. truncatula. As discussed above, the 57-bp spatial control region identified as essential for AtWUS promoter activity in the Arabidopsis stem cell niche (Baurle and Laux 2005) was absent from the MtWUS promoter.

The expression pattern of MtWOX5 is similar to MtWUS in the S3-S7 stages (Fig. 2i, m), and both genes participate in the formation of apical meristems at different poles of the embryo (Chen et al. 2009). Similar to MtWUS, expression of MtWOX5 in Medicago occurs later in embryogenesis relative to its Arabidopsis homologue (Haecker et al. 2004). It may be that before the heart stage, the actual establishment of stem cell niches in Medicago is performed by additional genes.

The $M$. truncatula homologue of Arabidopsis LATE MERISTEM IDENTITY1 (MtLMI1-like) encodes a Class I HD-ZIP protein with an expression profile that closely resembles $M t W U S$ (Fig. $2 \mathrm{i}, \mathrm{j}$ ). These two genes have two common promoter elements which suggest common targets for regulatory proteins to facilitate co-expression. RNA 
in situ hybridisation shows that unlike $M t W U S$, expression of MtLMII-like localises throughout the whole embryo at the torpedo stage with no expression in the hypophysis and suspensor, but with a concentration of signal in the forming vascular tissue (Fig. 4b, c). The Arabidopsis homologue promotes floral meristem identity (Saddic et al. 2006); but the Arabidopsis HD-ZIP protein AtHB-8 is associated with procambium development (Gardiner et al. 2010); while a HD-ZIP from tomato, VAHOX1, is involved in phloem development during secondary vasculature formation (Tornero et al. 1996).

Members of the KNOX gene family are necessary for maintaining the population of stem cells in the shoot apical meristem. SHOOT MERISTEMLESS (STM) functions to maintain central meristem cells in an undifferentiated state (Endrizzi et al. 1996) and has a complementary role to WUS in Arabidopsis shoot meristem regulation (Lenhard et al. 2002). The Class I MtKNOX6 gene (Mt5g093180) is STM-like (Di Giacomo et al. 2008) and has an expression profile similar to $M t W U S$ (Fig. $3 \mathrm{i}, \mathrm{k}$ ). The Class II MtKNOX4 gene (Mt5g011210) showed increased expression in torpedo-stage (S7) ovules and had a similar expression pattern to MtKNOX6 (Fig. 2k, 1). It is likely that MtKNOX4 and 6 play roles in shoot meristem formation in embryogenesis. MtWUS, MtWOX5, MtMLI1-like and MtKNOX6 (Fig. 5d) have common upstream GAGA elements, recognised by regulatory proteins in soybean (Sangwan and O'Brian 2002).

The expression profile of MtWOX11-like closely resembles that of MtWOX5, increasing in expression only during the latter stages of embryogenesis (S6-S7; Fig. 2n). Similarly, the grapevine homologue of MtWOX11-like is upregulated only in the later stages of somatic embryogenesis (Gambino et al. 2011). A homologue in rice (Os07g48560 in Supplementary Fig. 1A) is expressed in both shoot and root apical meristems and is involved in adventitious root formation (Zhao et al. 2009). Thus, MtWOX11-like might participate in the regulation of meristem formation during late embryogenesis in $M$. truncatula.

The BABYBOOM (MtBBM) gene belongs to the APETALA2 (AP2) family of transcription factors. $B B M$ in Arabidopsis was so-named for its capacity to induce somatic embryogenesis when ectopically expressed (Boutilier et al. 2002). $M t B B M$ is strongly up-regulated in torpedo-stage ovules (S7; Fig. 2p). In vitro, $M t B B M$ is also up-regulated in root primordia (Imin et al. 2007) and may be involved in the establishment of the root apical meristem. MtBBM and MtFUS3-like genes exhibited a similar expression profile and both genes contain common motifs in their $3^{\prime}$-UTR as determined by Mclip (Fig. 6b). While MtBBM and MtFUS3like have different cellular functions there is a substantive development of the embryonic root in legumes which also accumulates storage products (Wang et al. 2012).
The embryo maturation phase

The B3 domain-containing transcription factor family includes FUSCA3 (FUS3) and ABA INSENSITIVE3 (ABI3), which are involved in embryogenesis and seed filling (Giraudat et al.1992; Luerssen et al. 1998). MtFUS3-like and MtABI3-like both have high expression at the torpedo stage and negligible earlier expression, although MtFUS3-like expression starts slightly earlier (Fig. 2o, p). What is of interest is how early in embryogenesis the expression of the seed filling-related transcription factors initiate expression. MtABI3-like expression occurs throughout torpedo-stage embryos, but not in the hypophysis and suspensor. The expression of these two genes continues through the seedfilling stage (Thompson et al. 2009), but with MtFUS3-like expression declining earlier (Fig. 6).

Maximising the amount of storage product per seed is a combination of the size of the embryo and the amount of packaged storage product in each cell. Therefore, transcription activity in the S3-S5 stage of genes such as MtWOX 9-like and MtSERF 1 may be particularly important in affecting embryo size, while genes such as MtABI3 and MtFUS3 expressed subsequently influence the amount of storage product in each cell.

\section{Conclusions}

We developed a method of examining highly standardised stages of zygotic embryo development in M. truncatula. This enabled us to establish expression patterns of candidate transcription factors and their potential nexus. We presented data for 19 transcription factors that changed their expression during ovule formation and early embryogenesis. Transcription factors likely to play roles in ovule development, very early embryogenesis, midstage development and the development of the apical meristems were described. Expression of other transcription factors was associated with vascularisation and the onset of cotyledon development and seed storage. What is also of interest is how a number of transcription factors have peaks of expression in ovule and early embryo development as well as the torpedo stage. In some cases, co-expression of some genes could be related to common regulatory sequences in the promoter or $3^{\prime}$-UTR regions. Identifying stage-specific regulators is of great importance in providing approaches for functional studies. Maximising the amount of storage product per seed is a combination of the size of the embryo and the amount of packaged storage product in each cell. The genetic regulation of embryogenesis throughout all developmental stages needs to be understood to maximise the yields of storage products in legumes. 
Acknowledgments This work was supported by an Australian Research Council Centre of Excellence for Integrative Legume Research grant (CEO348212) to RJR. We thank Ross Pickett for technical assistance in the early stages of this project.

Open Access This article is distributed under the terms of the Creative Commons Attribution License which permits any use, distribution, and reproduction in any medium, provided the original author(s) and the source are credited.

\section{References}

Ariel F, Diet A, Verdenaud M, Gruber V, Frugier F, Chan R, Crespi M (2010) Environmental regulation of lateral root emergence in Medicago truncatula requires the HD-Zip I transcription factor HB1. Plant Cell 22:2171-2183

Baurle I, Laux T (2005) Regulation of WUSCHEL transcription in the stem cell niche of the Arabidopsis shoot meristem. Plant Cell 17:2271-2280

Benedito VA, Torres-Jerez I, Murray JD, Andriankaja A, Allen S, Kakar K, Wandrey M, Verdier J, Zuber H, Ott T, Moreau S, Niebel A, Frickey T, Weiller G, He J, Dai X, Zhao PX, Tang Y, Udvardi MK (2008) A gene expression atlas of the model legume Medicago truncatula. Plant J 55:504-513

Boutilier K, Offringa R, Sharma VK, Kieft H, Ouellet T, Zhang L, Hattori J, Liu C-M, van Lammeren AAM, Miki BLA, Custers JBM, van Lookeren Campagne MM (2002) Ectopic expression of BABY BOOM triggers a conversion from vegetative to embryonic growth. Plant Cell 14:1737-1749

Cannon SB, Sterck L, Rombauts S, Sato S, Cheung F, Gouzy J, Wang X, Mudge J, Vasdewani J, Schiex T, Spannagl M, Monagha E, Nicholson C, Humphrey SJ, Schoof H, Mayer KFX, Rogers J, Quétier F, Olroyd GE, Debellé F, Cook DR, Retzel EF, Roe BA, Town CD, Tabata S, Van de Peer Y, Young N (2006) Legume genome evolution viewed through the Medicago truncatula and Lotus japonicus genomes. Proc Natl Acad Sci USA 103:14959-14964

Cannon SB, May GD, Jackson SA (2009) Three sequenced legume genomes and many crop species: rich opportunities for translational genomics. Plant Physiol 151:970-977

Chen SK, Kurdyukov S, Kereszt A, Wang XD, Gresshoff PM, Rose RJ (2009) The association of homeobox gene expression with stem cell formation and morphogenesis in cultured Medicago truncatula. Planta 230:827-840

Choi HK, Kim D, Uhm T, Limpens E, Lim H, Mun JH, Kalo P, Penmetsa RV, Seres A, Kulikova O, Roe BA, Bisseling T, Kiss GB, Cook DR (2004) A sequence-based genetic map of Medicago truncatula and comparison of marker colinearity with M. sativa. Genetics 166:1463-1502

Cook DR (1999) Medicago truncatula - a model in the making! Curr Opin Plant Biol 2:301-304

Couzigou J-M, Zhukov V, Mondy S, Abu el Heba G, Cosson V, Ellis THN, Ambrose M, Wen J, Tadege M, Tikhonovich I, Mysore KS, Putterill J, Hofer J, Borisov AY, Ratet P (2012) NODULE and COCHLEATA maintain nodule development and are legume orthologs of Arabidopsis BLADE-ON-PETIOLE genes. Plant Cell 24:4498-4510

Di Giacomo E, Sestili F, Iannelli MA, Testone G, Mariotti D, Frugis G (2008) Characterization of KNOX genes in Medicago truncatula. Plant Mol Biol 67:135-150

Endrizzi K, Moussian B, Haecker A, Levin JZ, Laux T (1996) The SHOOT MERISTEMLESS gene is required for maintenance of undifferentiated cells in Arabidopsis shoot and floral meristems and acts at a different regulatory level than the meristem genes WUSCHEL and ZWILLE. Plant J 10:967-979

Felsenstein J (1989) PHYLIP: phylogeny inference package (version 3.2). Cladistics 5:164-166

Frickey T, Weiller G (2007) MClip: motif detection based on cliques of gapped local profile-to-profile alignments. Bioinformatics 23:502-503

Gambino G, Minuto M, Boccacci P, Perrone I, Vallania R, Gribaudo I (2011) Characterization of expression dynamics of WOX homeodomain transcription factors during somatic embryogenesis in Vitis vinifera. J Exp Bot 62:1089-1101

Gardiner J, Sherr I, Scarpella E (2010) Expression of DOF genes identifies early stages of vascular development in Arabidopsis leaves. Int J Dev Biol 54:1389-1396

Giraudat J, Hauge BM, Valon C, Smalle J, Parcy F, Goodman HM (1992) Isolation of the Arabidopsis ABI3 gene by positional cloning. Plant Cell 4:1251-1261

Goldberg RB, de Paiva G, Yadegari R (1994) Plant embryogenesis: zygote to seed. Science 266:605-614

Graham PH, Vance CP (2003) Legumes: importance and constraints to greater use. Plant Physiol 131:872-877

Groß-Hardt R, Lenhard M, Laux T (2002) WUSCHEL signaling functions in interregional communication during Arabidopsis ovule development. Genes Dev 16:1129-1138

Haecker A, Groß-Hardt R, Geiges B, Sarkar A, Breuninger H, Herrmann M, Laux T (2004) Expression dynamics of WOX genes mark cell fate decisions during early embryonic patterning in Arabidopsis thaliana. Development 131:657-668

Harris JC, Hrmova M, Lopato S, Langridge P (2011) Modulation of plant growth by HD-ZIP class I and II transcription factors in response to environmental stimuli. New Phytol 190:823-837

Hay A, Tsiantis M (2010) KNOX genes: versatile regulators of plant development and diversity. Development 137:3153-3165

Hirakawa Y, Kondo Y, Fukuda H (2010) TDIF peptide signaling regulates vascular stem cell proliferation via the WOX4 homeobox gene in Arabidopsis. Plant Cell 22:2618-2629

Huson DH, Richter DC, Rausch C, Dezulian T, Franz M, Rupp R (2007) Dendroscope: an interactive viewer for large phylogenetic trees. BMC Bioinforma 8:460

Imin N, Nizamidin M, Wu T, Rolfe BG (2007) Factors involved in root formation in Medicago truncatula. J Exp Bot 58:439-451

Ji J, Strable J, Shimizu R, Koenig D, Sinha N, Scanlon MJ (2010) WOX4 promotes procambial development. Plant Physiol 152:1346-1356

Karimi M, De Meyer B, Hilson P (2005) Modular cloning in plant cells. Trends Plant Sci 10:103-105

Larkin MA, Blackshields G, Brown NP, Chenna R, McGettigan PA, McWilliam H, Valentin F, Wallace IM, Wilm A, Lopez R, Thompson JD, Gibson TJ, Higgins DG (2007) Clustal W and Clustal X version 2.0. Bioinformatics 23:2947-2948

Lazo GR, Stein PA, Ludwig RA (1991) A DNA transformationcompetent Arabidopsis genomic library in Agrobacterium. Bio Technology 9:963-967

Le BH, Wagmaister JA, Kawashima T, Bui AQ, Harada JJ, Goldberg RB (2007) Using genomics to study legume seed development. Plant Physiol 144:562-574

Le BH, Cheng C, Bui AQ, Wagmaister JA, Henry KF, Pelletier J, Kwong L, Belmonte M, Kirkbride R, Horvath S, Drews GN, Fischer RL, Okamuro JK, Harada JJ, Goldberg RR (2010) Global analysis of gene activity during Arabidopsis seed development and identification of seed-specific transcription factors. Proc Natl Acad Sci USA 107:8063-8070

Lenhard M, Jürgens G, Laux T (2002) The WUSCHEl and SHOOTMERISTEMLESS genes fulfil complementary roles in Arabidopsis shoot meristem regulation. Development 129:3195-3206 
Luerssen H, Kirik V, Herrmann P, Misera S (1998) FUSCA3 encodes a protein with a conserved $\mathrm{VP1} / \mathrm{AB} 13$-like $\mathrm{B} 3$ domain which is of functional importance for the regulation of seed maturation in Arabidopsis thaliana. Plant J 15:755-764

Malik MR, Wang F, Dirpaul JM, Zhou N, Polowick PL, Ferrie AM, Krochko JE (2007) Transcript profiling and identification of molecular markers for early microspore embryogenesis in Brassica napus. Plant Physiol 144:134-154

Mantiri FR, Kurdyukov S, Lohar DP, Sharapova N, Saeed NA, Wang X-D, Vandenbosch KA, Rose RJ (2008) The transcription factor MtSERF1 of the ERF subfamily identified by transcriptional profiling is required for somatic embryogenesis induced by auxin plus cytokinin in Medicago truncatula. Plant Physiol 146:1622-1636

Mayer KFX, Schoof H, Haecker A, Lenhard M, Jürgens G, Laux T (1998) Role of Wuschel in regulating stem cell fate in the Arabidopsis shoot meristem. Cell 95:805-815

Mukherjee K, Brocchieri L, Bürglin TR (2009) A comprehensive classification and evolutionary analysis of plant homeobox genes. Mol Biol Evol 26:2775-2794

Muller PY, Janovjak H, Miserez AR, Dobbie Z (2002) Processing of gene expression data generated by quantitative real-time RTPCR. Biotechniques 32:1372-1379

Nardmann J, Zimmermann R, Durantini D, Kranz E, Werr W (2007) WOX gene phylogeny in POACEAE: a comparative approach addressing leaf and embryo development. Mol Biol Evol 24:2474-2484

Nolan KE, Kurdyukov S, Rose RJ (2009) Expression of the SOMATIC EMBRYOGENESIS RECEPTOR-LIKE KINASE 1 (SERK1) gene is associated with developmental change in the life cycle of the model legume Medicago truncatula. J Exp Bot 60:1759-1771

Park S, Harada JJ (2008) Arabidopsis embryogenesis. Methods Mol Biol 427:3-16

Rose RJ (2008) Medicago truncatula as a model for understanding plant interactions with other organisms, plant development and stress biology: past, present and future. Funct Plant Biol 35:253-264

Rose RJ, Mantiri FR, Kurdyukov S, Chen S-K, Wang X-D, Nolan KE, Sheahan MB (2010) The developmental biology of somatic embryogenesis. In: Pua EC, Davey MR (eds) Plant developmental biology_biotechnology perspectives, vol 2. Springer, Berlin, pp 3-26

Saddic LA, Huvermann B, Bezhani S, Su Y, Winter CM, Kwon CS, Collum RP, Wagner D (2006) The LEAFY target LMI1 is a meristem identity regulator and acts together with LEAFY to regulate expression of CAULIFLOWER. Development 133:1673-1682
Sangwan I, O'Brian MR (2002) Identification of a soybean protein that interacts with GAGA element dinucleotide repeat DNA. Plant Physiol 129:1788-1794

Simon P (2003) Q-Gene: processing quantitative real-time RT-PCR data. Bioinformatics 19:1439-1440

Su YH, Zhao XY, Liu YB, Zhang CL, O’Neill SD, Zhang XS (2009) Auxin-induced WUS expression is essential for embryonic stem cell renewal during somatic embryogenesis in Arabidopsis. Plant J 59:448-460

Tadege M, Lin H, Bedair M, Berbel A, Wen J, Rojas CM, Niu L, Tang Y, Sumner L, Ratet P, McHal NA, Madueño F, Mysore KS (2011) STENFOLIA regulates blade outgrowth and leaf vascular patterning in Medicago truncatula and Nicotiana sylvestris. Plant Cell 23:2125-2142

Tamura K, Peterson D, Peterson N, Stecher G, Nei M, Kumar S (2011) MEGA 5: molecular evolutionary genetics analysis using maximum likelihood, evolutionary distance and maximum parsimony methods. Mol Biol Evol 28:2731-2759

Thompson R, Burstin J, Gallardo K (2009) Post-genomics studies of developmental processes in legume seeds. Plant Physiol 151:1023-1029

Tornero P, Conejero V, Vera P (1996) Phloem-specific expression of a plant homeobox gene during secondary phases of vascular development. Plant J 9:639-648

Verdier J, Thompson RD (2008) Transcriptional regulation of storage protein synthesis during dicotyledon seed filling. Plant Cell Physiol 49:1263-1271

Verdier J, Kakar K, Gallardo K, Le Signor C, Aubert G, Schlereth A, Town CD, Udvardi MK, Thompson RD (2008) Gene expression profiling of $M$. truncatula transcription factors identifies putative regulators of grain legume seed filling. Plant Mol Biol 67:567-580

Wang X-D, Song Y, Sheahan MB, Garg ML, Rose RJ (2012) From embryo sac to oil and protein bodies: embryo development in the model legume Medicago truncatula. New Phytol 193:327-338

Wu X, Chory J, Weigel D (2007) Combinations of WOX activities regulate tissue proliferation during Arabidopsis embryonic development. Dev Biol 309:306-316

Young ND, Udvardi M (2009) Translating Medicago truncatula genomics to crop legumes. Curr Opin Plant Biol 12:193-201

Zhao Y, Hu Y, Dai M, Huang L, Zhou DX (2009) The WUSCHELrelated homeobox gene WOX11 is required to activate shootborne crown root development in rice. Plant Cell 21:736-748

Zheng Q, Zheng Y, Perry SE (2013) AGAMOUS-Like15 promotes somatic embryogenesis in Arabidopsis and soybean in part by the control of ethylene biosynthesis and response. Plant Physiol 161:2113-2127 